\title{
Clinical and Epidemiological Features of Tularemia
}

\author{
C. Ruef
}

In this issue of INFECTION, Chitadze et al. [1] report on an outbreak of oropharyngeal and glandular tularemia in the Republic of Georgia. We decided to publish this report because most infectious disease specialists have neither epidemiological nor clinical experience with tularemia. Only rarely is the diagnosis made in individual patients. It is unclear how often this diagnosis is missed in western European countries, for example. To witness and work up an outbreak of tularemia is most unusual. For all of these reasons, this report was considered to be a worthwhile contribution to the literature on this topic.

The study by Chitadze et al. has several interesting features, which make reading their report highly recommendable. One remarkable observation is that, in the majority of cases, the diagnosis was initially missed. This is somewhat surprising, since tularemia has been known as an infectious disease in the Republic of Georgia and having caused outbreaks there since 1946. In fact, between 1956 and 1985, vaccination against tularemia every 5 years was offered to the population of Georgia.

Another notable finding is the observation of neuropsychiatric symptoms, including depression and concentration difficulties, in about $50 \%$ of the patients. Furthermore, lymphadenopathy appeared to be of a rather chronic nature, persisting for 4 to 6 months. In addition to these features, the study by Chitadze et al. provides several other clinically relevant aspects, which will not be summarized here, as the original publication is suggested for reading.

In summary, tularemia as a rare disease should be considered in patients with fever, pharyngitis, and cervical adenitis, especially if the patient has visited remote areas and has consumed water that may have become potentially contaminated with Francisella tularensis. Appropriate diagnostic studies are warranted in such patients.

\section{Reference}

1. Chitadze N, Kuchuloria T, Clark DV, Tsertsvadze E, Chokheli M, Tsertsvadze N, Trapaidze N, Lane A, Bakanidze L, Tsanava S, Hepburn MJ, Imnadze P: Water-borne outbreak of oropharyngeal and glandular tularemia in Georgia: investigation and follow-up. Infection 2009; 37: 514-521. 